\title{
Towards a Framework of Trust Determinants in People and Cognitive Assistants Interactions
}

\author{
Md Abul Kalam Siddike \\ Japan Advanced Institute of \\ Science and Technology \\ kalam.siddike@gmail.com
}

\author{
Youji Kohda \\ Japan Advanced Institute of \\ Science and Technology \\ kohda@jaist.ac.jp
}

\begin{abstract}
The main purpose of this research is to develop a framework of trust determinants in the interactions between people and cognitive assistants (CAs). We define CAs as new decision tools, able to provide people with high quality recommendations and help them make data-driven decisions understanding the environment around people. We also define trust as the belief of people that CAs will help them reach a desired decision. An extensive review on trust in psychology, sociology, economics and policy making, organizational science, automation, and robotics is conducted to determine the factors influence people's trust on CAs. On the basis of this review, we develop a framework of trust determinants in people's interaction with CAs where reliability, attractiveness, and emotional attachment positively affect the intention of people in society to use CAs. Our framework also shows that innovativeness positively moderates the intention to use CAs. Finally, in this paper, we suggest future research directions for developing and validating more concrete scales in measuring trust determinants in the interactions between people and CAs.
\end{abstract}

\section{Introduction}

Today, Apple's Siri, Google's Now, Amazon's Eco, IBM's Watson, and other cognitive tools are beginning to reach a level of utility that provides a foundation for a new generation of cognitive collaborators and cognitive assistants (CAs) [49]. CAs are new decision tools, able to augment human capabilities and expertise in understanding the environment around us with depth and clarity [47] [48] [50-52]. CAs can provide people with highquality recommendations and help them make better data-driven decisions [6]. Trust is an important and essential issue to consider for CAs to be adopted by society. The progression from cognitive tool to assistant to collaborator to coach to mediator is in fact a progression of trust [50].
In the 19th century, people did not trust steam engines and "boilers." The problem was that they often exploded. Over time, design and engineering improved, trust went up, and economic growth resulted [50]. For example, consider this one application of the steam engine in America [2]; in 1850, a decade before the Civil War, the United States' economy was small-it wasn't much bigger than Italy's. Forty years later, it was the largest economy in the world. What happened in between was the railroads [2]. In the 21st century, people do not fully trust CAs. Knowledge, technology, and organizations are three ways people augment themselves to become smarter [34]. However, knowledge, technology, and organizations must be trusted to spur economic growth. Advanced cognitive systems must become trusted social entities to be effective in our culture [12]. Only as trusted social entities can cognitive systems augment human intellect and interact with people to co-create new knowledge, technology, and organizations [50].

In this paper, we reviewed trust-related literature in the fields of psychology, sociology, economics and policy making, organizational science, automation and robotics because doing so provides a broad view of trust in different fields. We searched different databases subscribed to by the Japan Advanced Institute of Science and Technology ${ }^{\mathrm{i}}$, Japan. We used several keywords. In addition, we also searched in Google Scholar. We selected those pieces of literature that were related to the current research purpose. Then, we conceptualized trust in CAs and developed a theoretical framework of trust determinants in the interactions between people and CAs.

Researchers in the above fields have focused on trust [4] [13] [17] [18] [20] [30-33] [36-37] [40] [45] [58] [27]. In psychology and sociology, researchers focused on interpersonal trust in close relationship [40]. Researchers from organizational science focused on organizational trust [30] [45]. In addition, researchers from economics focused on trust in 
information and trust in action for governing common resources [19] [36-37]. Furthermore, researchers from automation discussed the trust of people in reliance on automation [30-33]. Researchers from IS showed that technology trusting expectations influence trusting intention through performance, disconfirmation, and satisfaction [27]. In robotics, trust is described in terms the attractiveness of robots and the emotional feelings people have toward them [18] [58]. Furthermore, Alaieri and Vellino [1] described ethical robots that are able to make ethical decisions in a way that gives them some degree of responsibility.

In the case of personal assistants or CAs, Nunes, Barbosa, and de Lucena [35] theoretically described a domain-neutral user meta-model that allows highlevel user models to be used with configurations and preferences that increase users' trust on personal assistance software. In the same way, McGuinness, Wolverton and da Silva [31] explained that transparency (verification) and provenance (source of information) are the main factor in trusting cognitive assistants. However, no researcher has yet discussed how people trust their CAs in daily life. Therefore, the above research background clearly demands research into trust in CAs.

The main purpose of this paper is to conceptually develop a framework of trust determinants in the interaction between people and CAs as well as suggest future research for more concretely developing scales of trust determinants in these interactions. More specifically, we review literature on trust from psychology and sociology, organizational science, economics, automation and robotics to conceptualize trust in CAs. Then, we conceptualize determinants of trust and propose our framework of trust determinants. Finally, we conclude the paper by suggesting future research directions for developing scales for the framework of trust determinants in the interactions between people and CAs.

\section{Cognitive Assistants (CAs)}

CAs are new decision tools, able to augment human capabilities and expertise in understanding the environment around us with depth and clarity [48] [51-52]. CAs can provide people with high-quality recommendations and help them make better datadriven decisions [6]. The problem solving capabilities of people are significantly augmented by interacting with CAs [49-50]. In this paper, we define CAs as new decision tools, able to provide people with highquality recommendations and help them make better data-driven decisions by understanding the environment of people [47] [52]. CAs could come in different formats, such as speech (conversational agents), typing, and gestures (real robots). Nowadays, new technologies can augment the cognitive and social capabilities of people. Today, for example, cognitive computing and sensor technologies have begun to emerge and augment and scale the capabilities of people in specific ways [26] [39]. Cognitive systems can potentially progress from tools to assistants to collaborators and to coaches and be perceived differently depending on the role they play in a service system [50].

To be people-centered, this progression requires that cognitive systems recursively acquire more advanced models of their users in order to develop expert-level cognitive and social capabilities [47]. Eventually, CAs will exist for all types of occupations and societal roles in service systemsand this will be the dawn of the era of smart, peoplecentered service systems. The ownership of cognitive systems and the personal data on which they will operate - as CAs build user models - will become an active area of legislation in the coming years, as companies that produce intelligent personal assistants seek to monetize fully the benefits they create for customers [52].

\section{Trust}

In general, trust is considered to be a belief or attitude about others or a willingness to accept vulnerability or the behavioral state of vulnerability [25]. In this section, we review the components of trust from psychology and sociology (trust in close relationship), organizational science, economics, automation, and robotics to conceptualize trust in the interactions between people and CAs.

\subsection{Components of trust in close relationships}

Researchers from psychology and sociology discussed interpersonal trust in close relationships [7] [40] [43-44]. In close relationships, faith in partners helps to foster dependability and integrity [40]. Our review shows that willingness, confidence, predictability, dependability, faith, and integrity are the main components of trust in close relationships [7] [40] [43-44]. 


\subsection{Components of trust in organizations}

In organizations, people have to work in different self-directed teams, and each team collaborates with different teams. Trusting in teams means trusting the individuals of an organization. Mayer, Davis, and Schoorman [30] defined trust as the willingness of a party to be vulnerable to the actions of another party based on the expectation that the other will perform a particular action important to the trustor, irrespective of the ability to monitor or control that other party (p. 712). Our review shows that ability (competencies), benevolence (loyalty, openness, receptivity, availability of caring), and integrity (consistency, discreetness, fairness, promise, reliability, and value congruence) are the important components of trust [3] [15] [24] [30] [45].

\subsection{Components of trust in economics}

In economics, trust is related to trust in information and in action [19] [36-37]. Trust in information is related to actors (people, nations, agencies, and stakeholders) having to rely on information from different actors and sources in governing common resources in economics and policy making [19] [36-37]. Information is an important motivator in decision making in common governance systems, and trust in information is at least as important as trust in actions in supporting successful governance [19]. Trust in action is related to actors taking action on the basis of information [19] [36-37].

Table 1. Components of trust in different disciplines

\begin{tabular}{|l|l|l|}
\hline Components of Trust & Discipline & Authors \\
\hline $\begin{array}{l}\text { Willingness, confidence, predictability, } \\
\text { dependability, faith and integrity, group norms, } \\
\text { altruism, shared values, good will }\end{array}$ & $\begin{array}{l}\text { Trust in close } \\
\text { relationships }\end{array}$ & [7] [40] [43-44] \\
\hline $\begin{array}{l}\text { Ability (competencies), benevolence (loyalty, } \\
\text { openness, receptivity, availability of caring) and } \\
\text { integrity (consistency, discreetness, fairness, } \\
\text { promise, reliability, value congruence) }\end{array}$ & Organizational trust & [3] [15] [23] [45] [30] \\
\hline $\begin{array}{l}\text { Accuracy of information, trust in information, trust in } \\
\text { action }\end{array}$ & Trust in economics & [19] [36-37] \\
\hline $\begin{array}{l}\text { Reduced workload, reduced uncertainty, reduced risk } \\
\text { reliability, robustness, familiarity, accuracy, task } \\
\text { complexity, ability, predictability, dependability, } \\
\text { benevolence, openness }\end{array}$ & Trust in automation & [22] [28] [32-33] 38] [57] \\
\hline $\begin{array}{l}\text { Attractiveness, enjoyment, performance, attributes } \\
\text { Reliability, attractiveness, emotional attachment, } \\
\text { trustworthiness, innovativeness }\end{array}$ & Trust in robots & [58] \\
\hline
\end{tabular}

\subsection{Components of trust in automation}

Trust plays an influential role in reliance on automated systems [22] [32-33] [38]. Trust can affect how much people accept and rely upon increasingly automated systems [22]. Our review shows that most of the researchers [22] [25] [32-33] [38] adopted the components of trust from close relationships, organizations, as well as economics and applied them to measure users' trust toward automation. The components of trust in automation are ability, predictability, dependability, benevolence, openness, and risk.

\subsection{Component of trust in robots}

Trust toward robots mainly depends on the physical appearance and capabilities of the robots [18] [58]. Hancock et al. [18] stated that the performance and attributes of robots are the largest contributors to the development of trust in people and robot interaction. Yuksel, Collisson, and Czerwinski [58] mentioned that reliability and attractiveness are 
the main components of trust. In addition, researchers also noticed that trust depends on enjoyment and feeling like people are making contact with people (physical appearances).

\subsection{Component of trust in CAs}

Trust plays an important mediating role in reliance on automated systems [22] [32-33] [38]. In general, trust is considered to be a belief or attitude about others or the willingness to accept vulnerability or the behavioral state of vulnerability [25]. In this research, we define trust as the belief of people that CAs will help them to reach a desired decision. On the basis of the review of literature and our understanding of trust, it is found that reliability, attractiveness, and emotional attachments are the main components of trust in the interaction between people and CAs. In this case, innovativeness provides relative advantages to generating the trust of people.

\section{Towards Trust Determinants in Interactions between People and CAs}

On the basis of the discussion in the previous section, we conceptualize reliability, attractiveness, emotional attachments, trustworthiness, and innovativeness as being the important factors that play an influential role in the intention of people in society to use CAs. In this section, we describe the determinants of trust in the interaction between people and CAs.

\subsection{Perceived reliability}

System reliability is the most important element in trust in the interaction between people and CAs. A number of researchers have discussed similar constructs of reliability using several synonyms [14] [21] [25] [29] [32-33] [40] [42]. Researchers used the term "reliability" to express the ability and competency of a system to provide accurate information [7] [16] [33] [46]. In addition, some indicated functional/specific competency as well as capabilities of a system generate the reliability of the system [7] [39]. Some researchers indicated that predictability, dependability, and faith in a system denote the reliability of the system [32-33] [38] [40]. If a system is reliable, it ensures dependency, predictability, and the faith of people, so people use the system.

In this research, the term "reliability" denotes the abilities, capabilities, or competencies of CAs for providing high quality recommendations. People from different professions use CAs for different purposes on the basis of the reliability of the recommendations provided by CAs. Therefore, we predict that this reliability greatly influences people's intention to use CAs. As a result, we propose:

\section{Proposition 1: Perceived reliability positively affects} people's trust in using CAs.

\subsection{Perceived attractiveness}

In social psychology, the physical attractiveness of people is considered to be a positive personality trait [9]. Dion [8] described that adults view more attractive children's transgressions less negatively and view less attractive children's offenses as more of an enduring dispositional fault. Similarly, Efran [11] discussed that physically attractive defendants are found to be guilty less often and are given shorter sentences. Stewart [53-54] mentioned that attractiveness is highly predictive of both minimum and maximum sentences in judicial decisions in real courtrooms. Downs and Lyons [10] indicated that judges exhibited a strong attractiveness-bias in the bails and fines that they set.

In general, other people are attracted to handsome or beautiful people. The same thing happens in robots, technologies, or CAs. However, it is expected that CAs will become increasingly embodied in the future, so it seems unlikely that unattractive intelligent personal assistants will become the norm [58]. However, in the case of robots, they have attractive shapes and appearances, but in the case of attracting people to use CAs, attractiveness is considered to be in physical shapes as well as in the voice. We predict that attractiveness positively influences people's intention to use CAs. Therefore, we propose

\section{Proposition 2: Perceived attractiveness positively influences people's trustworthiness toward CAs.}

\subsection{Perceived emotional attachment}

In general, emotional attachment influences people to trust their partners, technologies, or pet robots. In the case of people, people interact with other people in a way in which they interact with their family members, friends, or people in their community, and they feel the emotions and values of others. In the same way, when people interact with pet robots, they feel a sense of emotion as if they were interacting with real pets. 


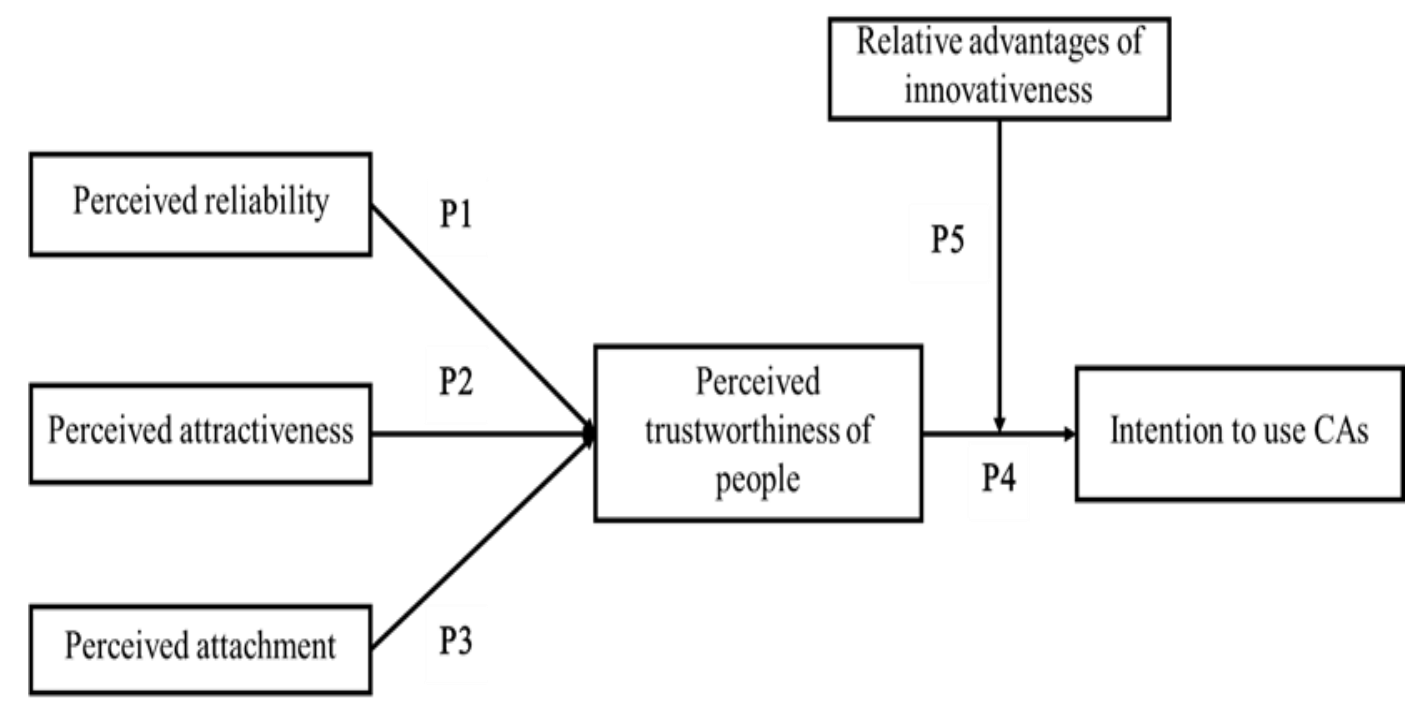

Fig. 1. Framework of trust determinants in people and CAs interactions

In this research, we consider emotional attachment as the feelings that people have when they are interacting with their CAs in a way similar to how they interact with their family members, friends, and people in their community. Therefore, we assume that emotional attachments positively influence people's trustworthiness toward using CAs in their various tasks.

Proposition 3: Perceived emotional attachments positively influence people's trustworthiness toward CAs.

\subsection{Perceived trustworthiness of people}

In general, people have the attitude or willingness to believe their partners [40]. This denotes people's faith in others [7]. In the case of economics, actors (people, organizations, or agencies) have the willingness to believe in the information or actions provided by other actors in order to govern common resources through deeds, contacts, rules, or other kinds of mechanisms [19] [36037]. In the case of organizations, people work in different teams, so team members have the tendency to trust in other team members [3] [15] [23] [30]. In a similar way, people have the willingness to trust in automation [22] [28]. In the same way, we believe that people will have the tendency to trust in their CAs. When CAs are reliable and attractive, people have more of an intention to use them for different purposes [5] [55-56]. In addition, when CAs produce more emotional feelings in people, people will have more of an intention to use them. As a result, people's trustworthiness toward CAs affects their intention to use CAs.

Therefore, we assume that people's trustworthiness toward CAs positively affects their intention to use CAs.

Proposition 4: People's trustworthiness toward CAs positively affects their intention to use CAs.

\subsection{Relative advantages of innovativeness}

Innovativeness provides relative advantages to users of a particular technology. In the theory of the diffusion of innovation, Rogers [41] indicated attributes of innovativeness, namely, relative advantage, compatibility, trialability, and observability. In this research, we consider innovativeness to be the relative advantages gained by users while using CAs. Therefore, we assume that the greater the rate of the innovativeness of CAs, the more rapidly CAs will be adopted in society. Therefore, we predict that innovativeness positively moderates the intention to use CAs.

Proposition 5: Innovativeness positively moderates the intention to use CAs.

\section{Framework of Trust Determinants}

In this section, we propose our framework of trust determinants for measuring people's trust toward CAs. 
Figure 1 shows our framework in the interaction between people and CAs.

Our framework has not been completed yet; it is still under development. In the framework, reliability, attractiveness, and emotional attachments are influential factors for generating trustworthiness of people in using CAs. First, reliability, in terms of the abilities, capabilities, or competences of CAs to provide high-quality recommendations, positively affects the people's trustworthiness toward using CAs (P1). Second, attractiveness in the form of physical shapes, attractive voices, or attractive sentences provided by CAs positively influences people's trustworthiness toward using CAs (P2). Third, emotional attachments also positively affect people's trustworthiness toward using CAs (P3). Fourth, people trustworthiness toward CAs positively affects the intention of people in society to use CAs (P4). Finally, innovativeness positively moderates the intention to use CAs, as innovativeness provides the relative advantages of using CAs (P5).

\section{Discussion and Future Research Directions}

The main purpose of this research was to develop a framework of trust determinants for measuring people's trustworthiness toward using CAs. In this framework, reliability, attractiveness, and emotional attachments are influential factors for generating the trustworthiness of people toward using CAs. In addition, innovativeness also positively moderates the intention of people to use CAs. Our framework is still under development.

Our framework provides an opportunity for humancomputer interaction, system science, and cognitive computing researchers as well as service science researchers to quantitatively measure trust determinants in the interaction between people and CAs through the development and validation of concrete scales. We also believe that designers and engineers will greatly benefit from our framework through its more people-centric design. Last but not least, system science, cognitive computing, as well as service science disciplines will also be greatly benefited through the use of our framework.

This research is not free from limitations. First of all, our framework is based on a literature review and our understanding of trust and CAs. Second, the framework is conceptual and has not been validated yet. However, we provide several propositions for developing concreate measurement scales as part of a future research agenda. Initially, a series of workshops (discussions) could be arranged for getting feedback from engineers, designers, academics, and users from all over the world to gain a deeper understanding and to further improve our trust-determinant framework. In the second phase, we could conduct interviews with engineers, designers, academics, as well as users of CAs globally. Next, we could concretely develop constructs or variables for our framework. Furthermore, we could survey engineers, designers, academics, and users to validate and justify our framework. Finally, we could develop our final version of the trust-determinant framework on the basis of data obtained in the several phases as well as also use simulations and mathematics.

\section{Acknowledgements}

This research is supported by a scholarship from the Ministry of Education, Culture, Sports, Science and Technology (Monbukagakusho) at the Japan Advanced Institute of Science and Technology, Japan.

\section{References}

[1] F. Alaieri and A. Vellino, "Ethical decision making in robots: Autonomy, trust and responsibility," In International Conference on Social Robotics, 2016, pp. 159-168, Springer International Publishing.

[2] W. B. Arthur, "The second economy," McKinsey Quarterly, 4, 2011, pp. 90-9, URL (accessed July 6, 2017): http://www.fullertreacymoney.com/system/data/images/archi ve/2011-10-10/TheSecondEconomy.pdf

[3] J. K. Butler, "Toward understanding and measuring conditions of trust: evolution of a conditions of trust inventory," Journal of Management, 17, 1991, pp. 643-663.

[4] A, Costa, S., Heras, J. Palanca, P. Novais, and V. Julián, "A persuasive cognitive assistant system," In Ambient Intelligence-Software and Applications-7th International Symposium on Ambient Intelligence, 2016, pp. 151-160, Springer, Cham.

[5] F. D. Davis, "Perceived usefulness, perceived ease of use and user acceptance of information technology," MIS Quarterly, 13(3), 1989, pp. 319-340.

[6] H. Demirkan, C. Bess, J. Spohrer, A. Rayes, D. Allen, and Y. Moghaddam, "Innovation with smart service systems: Analytics, big data, cognitive assistance and the internet of everything," Communications of the Association for Information Systems, 37, 2015, pp. 733-752.

[7] M. Deutsch, "The effect of motivational orientation upon trust and suspicion," Human Relations, 13, 1960, pp. 123140.

[8] K. Dion, "Physical attractiveness and evaluation of children's transgressions," Journal of Personality and Social Psychology, 24(2), 1972, pp. 207-213.

[9] K. Dion, E. Berscheid, and E. Walster, "What is beautiful is good," Journal of Personality and Social Psychology 24(3), 1972, pp. 285-290.

[10] C. A. Downs and P. M. Lyons, "Natural observations of the links between attractiveness and initial legal judgments," 
Personality and Social Psychology Bulletin, 17(5), 1991, pp. 541-547.

[11] M.G. Efran, "The effect of guilt, of physical appearance on the judgment severity interpersonal attraction, and of recommended punishment in a simulated," Journal of Research in Personality, 8, 1974, pp. 45-54.

[12] K. D. Forbus, "Software Social Organisms: Implications for Measuring AI Progress," AI Magazine, 37(1).

[13] C. Friemel, S. Morana, J. Pfeiffer, and A. Maedche, "On the role of users' cognitive-affective states for user assistance invocation," in Proceedings of the Gmunden Retreat on NeuroIS, Gmunden, Austria, June 2017.

[14] T. Frost, D. V. Stimpson, and M. R. C. Maughan, "Some correlates of trust," Journal of Psychology, 99, 1978, pp. 103-108.

[15] J. Gabarro, "The development of trust, influence, and expectations," in A. G. Athos \& J. J. Gabarro (Eds.), Interpersonal behavior: Communication and understanding in relationships: 290-303, Prentice Hall, Englewood Cliffs, NJ, 1978.

[16] D. Good, "Individuals, interpersonal relations, and trust," in D. G. Gambetta (Ed.), Trust, Basil Blackwell, New York, 1988, pp. 131-185.

[17] M. Garcia, "Racist in the machine: the disturbing implications of algorithmic bias," World Policy Journal, 33(4), 2016, 111-117.

[18] P. A. Hancock, D. R. Billings, K. E. Schaefer, J. Y. C. Chen, E. J. de Visser, and R. Parasuraman, "A meta-analysis of factors affecting trust in human-robot interaction," Human Factors, 53(5), 2011, pp. 517-527.

[19] A. D. Henry and T. Dietz, "Information, networks, and the complexity of trust in commons governance," International Journal of the Commons, 5(2), 2011, 188-212.

[20] K. A. Hoff and M. Bashir, "Trust in automation: Integrating empirical evidence on factors that influence trust," Human Factors, 57(3), 2015, pp. 407-434.

[21] C. I. Hovland, I. L. Janis, and H. H. Kelley, "Communication and persuasion," Yale University Press, New Haven, 1953.

[22] J. Y. Jian, A. M. Bisantz, and C. G. Drury, "Foundations for an empirical determined scale of trust in automated systems," International Journal of Cognitive Ergonomics, 4(1), 2000, pp. 53-71.

[23] A. P. Jones, L. R. James, and J. R. Bruni, "Perceived leadership behavior and employee confidence in the leader as moderated by job involvement," Journal of Applied Psychology, 60, 1975, pp. 146-149.

[24] A. P. Jones, L. R. James, and J. R. Bruni, "Perceived leadership behavior and employee confidence in the leader as moderated by job involvement," Journal of Applied Psychology, 60, 1975, pp. 146-149.

[25] H. W. Kee and R. E. Knox, "Conceptual and methodological considerations in the study of trust," Journal of Conflict Resolution, 14, 1970, pp. 357-366.

[26] J. E. Kelly III and S. Hamm, "Smart machines: IBM's Watson and the era of cognitive computing," Columbia University Press, New York, 2013.

[27] N. Lankton, D. H. McKnight, and J. B. Thatcher, "Incorporating trust-in-technology into Expectation Disconfirmation Theory," The Journal of Strategic Information Systems, 23(2), 2014, 128-145. IS
[28] J. D. Lee, and K. A. See, "Trust in automation: Designing for appropriate reliance," Human Factors, 46(1), 2004, pp. 50-80.

[29] J. K. Lieberman, "The litigious society," Basic Books, New York, 1981.

[30] R. C. Mayer, J. H. Davis, and F. D. Schoorman, "An integrative model of organizational trust," Academy of Management Review, 20(3), 1995, pp. 709-734.

[31] L. D. McGuinness, A. Glass, M. Wolverton, and P. P. da Silva, "Explaining task processing in cognitive assistants that learn," In AAAI Spring Symposium: Interaction Challenges for Intelligent Assistants, 2007, pp. 80-87.

[32 B. M. Muir, "Trust in automation: part 1. Theoretical issues in the study of trust and human intervention in automated systems," Ergonomics, 37(11), 1994, pp. 19051922.

[33] B. M. Muir and N. Moray, "Trust in automation: part II. Experimental studies of trust and human intervention in a process control simulation," Ergonomics, 39(3), 1996, pp. 429-460.

[34] D. A. Norman, "Things that make us smart: defending human attributes in the age of the machine," Basic Books, New York, 1993.

[35] I. Nunes, S. D. Barbosa, and C. J. de Lucena, "Increasing users' trust on personal assistance software using a domain-neutral high-level user model," in International Symposium on Leveraging Applications of Formal Methods, Verification and Validation, 2010, pp. 473-487, Springer, Berlin, Heidelberg.

[36] E. Ostrom, "Toward a behavioral theory of linking trust, reciprocity and reputation," in E. Ostrom and J. Walker (Eds.), Trust \& Reciprocity: Interdisciplinary Lessons from Experimental Research, Russel Sage Foundation, New York, 2003, pp. 19-79.

[37] E. Ostrom and J. Walker, "Introduction," in E. Ostrom and J. Walker (Eds.), Trust \& Reciprocity: Interdisciplinary Lessons from Experimental Research, Russel Sage Foundation, New York, 2003.

[38] P. Parasuraman and V. Riley, "Humans and automation: use, misuse, disuse, abuse," Human Factors, 39(2), 1997, pp. 230-253.

[39] A. Pentland, "Honest signals: How they shape our world," The MIT Press, Massachusetts, 2008.

40] J. K. Rempel, J. G. Holmes, and M.P. Zanna, "Trust in close relationships," Journal of Personality and Social Psychology, 49(1), 1985, pp. 95-112.

[41] E. M. Rogers, "Diffusion of innovations," Free Press, New York, 2003.

[42] B. Rosen and T. H. Jerdee, "Influence of subordinate characteristics on trust and use of participative decision strategies in a management simulation," Journal of Applied Psychology, 62, 1977, pp. 628-631.

[43] J. B. Rotter, "Interpersonal trust, trustworthiness, and gullibility," American Psychology, 35, 1980, pp. 1-7.

[44] J. Scanzoni, "Social exchange and behavioral interdependence," in R. L. Burgess \& T. L. Huston (Eds.) Social exchange in developing relationships, Academic press, New York, 1979.

[45] F. D. Schoorman, R. Mayer, and J. H. Davis, "An integrative model of organizational trust: Past, present, and 
future," Academy of Management Review, 32(2), 2007, pp. 344-354.

[46] S. B. Sitkin and R. J. Bies, "The legalization of organizations: A multi theoretical perspective," in S. B Sitkin \& R. J. Bies (Eds.), The legalistic organization, Sage, Thousand Oaks, CA, 1994, pp. 19-49.

[47] M. A. K. Siddike, K. Iwano, K. Hidaka, Y. Kohda, and J. Spohrer, "Wisdom service systems: Harmonious interactions with people and machines," in L.E. Freund and W. Cellary (eds.), Advances in The Human Side of Service Engineering, AHFE 2017, Advances in Intelligent Systems and Computing 601, Cham, Springer.

[48] J. Spohrer, "Innovation for jobs with cognitive assistants: a service science perspective," in Disrupting Unemployment (Ed. Nordfors, Cerf and Senges), Ewing Marion Kauffman Foundation, Missouri, USA, 2016.

[49 J. Spohrer and G. Banavar, "Cognition as a service: An industry perspective," AI Magazine, 36(4), 2015, pp. 71-86.

[50] J. Spohrer and M. A. K. Siddike, "The future of cognitive mediators: tool, assistant, collaborator, coach," Peter Lang Publishing, New York, 2017 (in press).

[51] J. Spohrer, C. Bassano, P. Piciocchi, and M. A. K. Siddike, "What makes a system smart? wise?", Advances in The Human Side of Service Engineering, 2017, pp. 27-31.

[52] J. Spohrer, M. A. K. Siddike, and Y. Kohda, "Rebuilding evolution: A service science perspective," in

http://www.jaist.ac.jp/library/english/internal/search/ outsidedb.html
Proceedings of the 50th Hawaii International Conference on System Sciences, Hilton Waikoloa Village, Hawaii 4-7 January, 2017, pp. 1663-1672.

[53] J. E. Stewart, "Defendant's attractiveness as a factor in the outcome of criminal trials: An observational study," Journal of Applied Social Psychology 10(4), 1980, pp. 348361.

[54] J. E. Stewart, "Appearance and punishment: The attraction-leniency effect in the courtroom," Journal of Social Psychology 125(3), 1985, pp. 373-378.

[55] V. Venkatesh, M. G. Morris, G. B. Davis, and F. D. Davis, "User acceptance of information technology: Toward a unified view," MIS Quarterly, 27(3), 2003, pp. 425-478.

[56] W. Wang and I. Benbasat, "Trust in and adoption of online recommendation agents," Journal of the Association for Information Systems, 6(3), 2005, pp. 72-101.

[57] J. Xu, K. Le, A. Deitermann, and E. Montague, "How different types of users develop trust in technology: A qualitative analysis of the antecedents of active and passive user trust in a shared technology," Applied Ergonomics, 45(6), 2014, pp. 1495-1503.

[58] B. F. Yuksel, R. Collison, and M. Czerwinski, "Brains or beauty: How to engender trust in user-agent interactions," ACM Transactions on Internet Technology, 17(2), 2017, pp. $1-20$. 